\title{
Marsha Berry
}

\author{
Poetic Tweets
}

\begin{abstract}
In this paper, I explore some implications of social software for literary studies and expose how it enables participation in creative practice communities that are integrated into daily social activities. Twitter has become an integral part of my creative practice as an artist and poet. The forms are constrained by the limitations of 140 characters; however, this limitation is the midwife to innovative uses of language as well as to the resurgence of old forms like haiku. Twitter offers creative writers ways of participating and collaborating in global online poetry communities where writing takes on a performance as well as a social dimension.
\end{abstract}

Keywords: poetry, social media, writing as performance

\section{Poetics of new media}

Social media has significantly changed the landscape of cultural production. Leadbeater (2009) suggests that social media allows for the democratisation of communication across a range of contexts presenting a substantial challenge for the old hierarchies and social roles of traditional models of publishing and mass media. Traditional media and consumption / production paradigms have shifted substantially since the advent of convergent social media. The consumption / production model is no longer top down with the media industry controlling information flows, rather content often bubbles up from users of social media. Many publishers encourage authors to use Twitter and Facebook to maintain a strong and current online presence as a part of a broader marketing strategy.

Writers can also readily experiment and produce innovative forms within the terrain created by social media where 'creative vernaculars' (Burgess 2008) that give expression to specific identities, personas and communities are surfacing. As a site of introjection as well as projection, it gives rise to spaces where social controls are in flux, where people can create and consign meaning and can intervene in the world to make an impact, or to influence others. Social media is personal as well as political and resides in the imaginary as well as in the social. I propose it is also the symbolic 'Other' (Lacan 1977), which challenges pre-existing social orders, structures and conventions of language use as well as a creative play space for performances (Schechner 2002).

The use of social media for literary expressions is a deviation from more traditional print forms; it can spawn negative feelings about participation in a world that challenges older paradigms of dissemination. The poetics of new media is an emerging field of intellectual enquiry while literary studies is well established in academic circles. Raley (2009), in a paper presented to the 
Digital Arts and Culture Conference, confronts this debate to argue that a robust concept of reading needs to include mobile communication technologies as well as print. I would add that the economical use of words is a direct consequence of the use of mobile and social media.

During the late 1990s in Japan, SMS was used to text serialised narrative works in episodes or chapters of around 100-200 words to be read on mobile phones (keitai). The phenomenon of Japanese mobile phone novels has been widely cited as evidence of the transformational qualities of mobile media; some contempt has been expressed in critiques in mainstream media labelling the novels as adolescent and genre-based, even shallow; for example, Jane Sullivan said that Japanese mobile phone novels suffer from 'quality control' (Sullivan 2008: 28). However, as Coates observes keitai shõsetsu stretch reading practices as well as writing:

unusual orthographical features found in keitai shousetsu, focusing on emoticons, symbols, non-standard punctuation and unconventional script choice and size, [result] in a novel which is appealing and easily accessible to young people. (Coates 2010: 1)

Furthermore keitai shõsetsu have their origins in 'high' Japanese literature such as Murasaki's The Tale of Genji. They incorporate the poetics of traditional Japanese literary canons so that 'keitai shõsetsu must be conceptualised as an extension of older media practices and epistolary traditions' and further they 'invoke the art of haiku poetry' (Hjorth 2009: 35). In short, mobile phone novels have expanded both reading and writing practices to embrace mobile technology, as well as to connect with established canons of Japanese literature.

A new shorthand form of language associated with the use of SMS is a global phenomenon that causes debates as to whether standards of English usage are declining or not (see for example, Debman 2010). Notwithstanding, mobile and social media technologies have taken literary practices into new territories. Susan Hayes (2011) in a recent article claims that she has 'seen digital writing and publishing moving rapidly from the margins into the mainstream'. Furthermore, social software enables engagement and participation in creative writing that is integrated into daily social activities. Not only can people use mobile technology to micro-manage banalities, they can use them to engage with language acts that seek to ignite the imagination.

The potential of Twitter for innovative writing is exemplified in Twitterature where the authors Aciman and Rensin (2009) present condensed versions of canonical literature in sequences of tweets. Their introduction concludes with an invitation:

And allow us now to open

The eternal aperture,

To the brilliant soul of common man:

We now present you ... Twitterature. (Aciman \& Rensin 2009: $\mathrm{xvi})$

Neil Gaiman was also inspired enough by the potential of Twitter to compose an audio-book in 2009 called Hearts, Keys and Puppetry in collaboration with 'the Twitterverse' (Gaiman \& the Twitterverse 2009). The project commenced with Gaiman's tweet:

Sam was brushing her hair when the girl in the mirror put down the hairbrush, smiled \& said, 'We don't love you anymore.'

@BBCAA \#bbcawdio (Celebrity Tweet 2011) 
Other Twitter users were invited to join and BBC Audiobooks America compiled the final version. Over a hundred people contributed to this collaboration. So what is it about Twitter that inspires experimentations with poetic forms of writing?

\section{Twitter as a poetry machine}

Poetic language is a literary genre that may be characterised by the use of prosodic patterns or metre; tropes including metaphors, metonymies, personification; schemes ordering words and syntax, including unconventional use of normal speech; and lines of text broken up according to the number of syllables (Abrams \& Harpham 1999: 194). It uses 'similarities in form and position among certain words in the text, similarities that are rationalized and interpreted in terms of meaning' (Riffaterre 1983: 36). Poetic language, then works though systems of descriptions so that the semantics of a poetic expression positions the reader to engage in a process of accumulation to ascribe meaning and to draw syntagmatic connections or associations between constellations of words (Riffaterre 1983: 12). In Twitter, forms and structures of writing are constrained by the limitations of 140 characters where each character is a letter, a space or punctuation mark. Expressions need to be concise and vivid to have impact. I propose that this limitation is the midwife to unprosaic uses of language.

In 2007, Tom Watson noticed that Twitter posts used language in ways that suggested poetry. He claimed it was 'a poetry machine' (Watson 2007) because of both the language usage in individual tweets as well as the juxtaposition of tweets. His initial reaction to Twitter was contempt for yet another networked streaming messaging system that demands attention. What changed his mind was a tweet he received from Steve Bowbrick:

Driving down to West Cork used to be a quiet pleasure.

Now it's a melancholy chore.

Still, the sky is absolutely full of stars. (Watson 2007)

This inspired him to examine how people used words given the constraints of 140 characters. He found the constraints of the medium could encourage thoughtful minimalist language use. He used tweets as found objects to construct this poem:

\section{One}

Pouring another cup of coffee and trying to get motivated Revelling in plying the Clash at inappropriate levels of volume Napping is seriously heaven.

Rip, mix, burn. (Watson 2007)

The Longest Poem in the World also uses found objects in the form of tweets. In May 2010 it was already 1,009,852 verses in length. Its creators compile the poem from Twitter streams and use a carefully scanned rhyming structure. Below is an extract from 17 May 2010:

Milan and Verona tomorrow ... Anyone around?

My fists clench as my heart and mind both begin to pound.

Looks like the set from the krypton factor ... and equipment to match.

my cousins are over and they made me a red velvet cake from SCATCH.

there's birds in my roof and they've been squawking all day K. 
Hi all $\sim$ and what a lovely day it is today $\sim \sim$

And that, gentlemen, is my sole motivator for today. (Gheorghe $n d)$

Each line was a separate tweet to its own audience and from its own context, yet here they combine to produce a poetic sequence inviting a reader's interpretation. The poem plunders collective streams of consciousness using an exquisite corpse-like device popularised by the Dada movement and also used later by Beat Generation writers like William Burroughs. This method is also known as the cut-up technique. In contrast to Modernist experiments with language captured in print and collages, this experiment has impermanence built in. Although it is possible to scroll through the whole poem, the most recent tweets appear on the first page, the rest are archived and require effort to find. The Longest Poem will be different tomorrow and in a year will be difficult to find in the configuration above. It has resonance with Borges' Book of Sands (1975), which was a mythical book where the same page never appeared twice: it changed every time it was read. Almost a year later, I revisited The Longest Poem in the World (6 April 2011) and the first lines read:

ever though you're singing and thinking how well you've got it made.

I just looked at this week's calendar and I'm very afraid.

And suddenly I'm not sleepy anymore. I'd die for some cereal.

Crap. I have to take a dump and I am out of reading material.

YOU ARE MY FRIEND and I LOVE YOU!

Night of Champions: Cody and Drew!

Took my money. Took my bitch from me. And took my crew.

\#takers

Future decision makers; become the movers and shakers

Left one event and now at another

Dancing to rap with ron and his mother. :)

I like big butts and I can not lie. (Gheorghe nd)

\section{Streams of poetry}

Twitter has its own terminology with terms referring to specific actions. For example, the term 'follow' refers to those people I have subscribed to so that I can see their status updates appear in my timeline or stream. 'Follower' refers to people who have subscribed to me and have my updates appear in their stream. 'Tweet' refers to a status update; 'retweet' refers to a status update being forwarded by a follower. 'Stream' refers to a timeline where tweets appear. The stream can be organised into threads according to topics similarly to a discussion forum. To distinguish between various post threads hash tags (\#) are used. These operate in a similar way to keywords in search engines and are used within Twitter to structure content according to categories or threads. Users can create hash tags to focus discussion on a specific topic such as the disruption of flights due to the Icelandic volcano, to aggregate commentary on events such as the Iran election and the earthquake in Japan or to classify poetic tweets according to form such as haiku.

Twitter is not only a poetry machine; it is also public space, giving rise to communities with their own tacit conventions of exchange, challenges, ripostes and gift giving. There is in this space a 'sense of honour' similar to what Bourdieu described (Bourdieu 1977: 15) that is both inscribed within the Twitter platform as well as in the social activities and rituals that take place around tweeting and retweeting. A 'sense of honour' is intrinsic to a 
community's logic of practice whereby it is '...the cultivated disposition, inscribed in the body schema and in the schemes of thought, which enables each agent to engender all the practices consistent with challenge and riposte...' (Bourdieu 1977: 15). In other words, a sense of honour maintains harmonious relations within a community while at the same time accommodating rigorous debates with opposing points of view.

Poets who use Twitter get to know each other and each other's work through streams, retweets and hash tags. They form communities governed by exchange, reciprocity and a sense of honour. There are cycles of reciprocity where the significance of a 'retweet' is conflated with notions of exchange and gift giving. Phatic expressions including emoticons are exchanged to maintain relationships. Twitter has created public forums for a twenty-first century renaissance of medieval poetic forms such as haiku, senryu and tanka.

The aesthetics of Japanese poetry forms are derived from Zen so that themes of natural beauty, love, the impermanence of life, everyday activities and separation are very common. They are composed with the priorities of 'to be touched by things', to create 'ah-ha' moments and to use concrete images. The following poem by the seventeenth century Japanese poet Matsuo Bashõ (1644-1694) who is recognised internationally as one of the most famous poets of the Edo period exemplifies these aesthetics:

No one but myself

Goes along this road at dusk, The end of autumn. (Kikaku 2006)

In the early twentieth century his works were translated into English. The simplicity and depth of Bashõ's imagery had a profound influence on avantgarde poets such as Ezra Pound and the Imagist movement as well as Beat Generation poets such as Kerouac, Ginsberg and Burroughs (Lawlor 2005).

Pound re-imagined aesthetic principles from haiku and other short forms of canonical poetry from Japan to create a new school of poetry as a reaction against the ornamental language of the Victorian poets. He identified three key principles to govern the aesthetics of Imagist poetry. First the poem needs to address the 'thing' directly; second, there should be absolutely no extra words, and third, the rhythm should be composed in sequences akin to musical phrases rather than following a regular beat (Ayers 2004). Traditionally there was a syllable count associated with forms such as 5/7/5 for haiku in English and 5/7/5/7/7 for tanka; however, modern American haiku no longer adheres to this convention as evidenced by the selections in poetry journals such as Acorn, Prune Juice, Simply Haiku and American Tanka.

These forms are still being reinterpreted for use in the English language and are persistent as hash tags streams in Twitter. \#Haikuchallenge is an example of one such stream. Each day poets use the hash tag to post their haiku containing a specific word. One of the regular participants will nominate a word to be used in haiku for that day. The sequence of haiku below was collected from twitter feeds on 23 May 2011. The challenge word was 'use':

\author{
daphnepurpus Daphne Purpus \\ the crows hoodwink / sparrows to use / random flight patterns \\ // \#haikuchallenge \#lqw \#arwiculate \\ 1 hour ago Favorite Retweet Reply \\ Dechenlhamo Heather Buttle \\ I am determined / to put this mind to good use / even on
}


Mondays \#iKu \#haikuchallenge \#haiku

3 hours ago Favorite Retweet Reply

JDProuty J. D. Prouty

Seek to be useful; you'll feel blissfully used by $\sim$ the end of the day. \#haikuchallenge (use) \#senryu

5 hours ago Favorite Retweet Reply

These poems show a clear debt to both the Imagists and the Beat Generation. They also pay homage to Zen aesthetics.

\section{Performing tweets}

There is oscillation between people, poems and words in Twitter hash tag streams. If I choose to join, my hope is that my haiku tweet will be 'retweeted' by others to live further along in the stream and that followers will respond with a comment or a verse of their own. Jumping into the stream of a haiku, tanka, gogyohka (contemporary Japanese short form poetry akin to tanka) or senryu (Japanese short form wry self-referential poetry akin to haiku) hash tag is an act of improvisation and dialogue as well as a practice and performance a form of public art.

The nature of the occasion, the genre and an awareness of the audience are all paramount. Allsop notes:

the conventionalized (and therefore often unquestioned) relations between writing and performance are proving increasingly inadequate as interdisciplinary and crossdisciplinary arts practices emerge in response to rapidly shifting cultures. (Allsop 1999: 76)

Within Twitter contexts, the act of writing becomes performance as well as communication. When thinking about performance within the expanded field of online social life, it is still relevant to consider representation, simulation, presence and the subjunctive 'what if' as well as the elusive indicative 'as if' (Schechner 2002).

In Twitter, people do not always use their real names. Pseudonym user names are as commonplace as real names. Others treat these as if they were 'real' names. Friendships and bonds develop between people as if they knew each other in the physical world. There is a tacit understanding that one should not ask questions concerning place of employment or study, occupation, marital status, etc, in the public stream. (Twitter has included a private one-to-one direct message function for such questions and for more intimate interactions.)

This is because many treat Twitter as a play space where they can be 'the joker in the deck' through engaging in 'the supreme bricoleur frail transient constructions, like a caddis worm or a magpie's nest' (Schechner 2002: 80) where much behaviour involves subjunctive spaces and restored behaviour. 'Restoration' is a term Schechner uses to refer the main characteristic of performance where living behaviour is 'treated as a film director treats a strip of film' (Schechner 1985: 35). It may be put on in much the same way as a mask and is always subject to revision. It is symbolic and reflexive, so that the self can act as if it were another is 'twice-behaved behavior' (Schechner 1985: 36) in that it can be worked on and changed. Twitter may be conceptualised as a stage where the play has no script and no apparent structure where sometimes group collaborations happen quite spontaneously. There are entrances and exits 
with lines delivered by players with names such as bookwriter222; where continuums operate in terms of how various selves present themselves to themselves and to others, and how they revise their performances over time.

This has parallels with the process an actor undergoes to create a liminoid state of 'not not me' (Schechner 1985: 113) when entering a rehearsal or performance space to create a three-dimensional performance text. In theatre and performance art, selves move between the present grounded here and now and imaginary worlds. Lived experience shifts between these states as "performance "takes place in the not me ... not not me" between performers; between performers, texts, and environment; between performers, texts, environments and audience' (Schechner 1985: 113). The Twitter space provides selves with a liminal / liminoid space in which to play and to explore the relationships of textually inscribed personas and bodies. People experiment with personas, which may be regarded as performances.

To join a particular poetry hash tag stream implies an awareness of other performers, texts, audience as well as one's own subject position within a writing act. It may include inhabiting strange bricoleurs of transient and ephemeral structures in order to create and restore subjunctive spaces. Imaginary courtly Japanese houses with elegant gardens and ponds are examples of such a bricoleur structure, which may be restored and inhabited through a renga performance within a hash tag poetry stream. Renga is a literary art form written by two or more collaborators that was popular in Japan during the medieval and Edo periods. Bashõ was a keen proponent and innovator of the form. As well as being poetry, renga is an improvisation where two or more poets collaborate to produce a performance through linked verse. Its popularity declined during the Meiji period when Japanese poetry became influenced by Western forms where the emphasis was on the work of an individual poet rather than on collaborations. Ronan describes the writing of renga thus:

While engaged in contributing to a renga the writers are aware that a careless, uneducated reader could find the completed poem merely a crazy-quilt assemblage of alternating two and three line stanzas. However, they also know that a knowledgeable, sensitive reader will legitimately anticipate a creative, meaningful and enjoyable assemblage of organized stanzas. Writers of renga design their lines so that ANY ADJACENT SET of two and three lines will have a subtle but recognizable relationship. (Ronan 1995)

Reichhold offers the following advice to readers:

As you read some of the renga the important thing to watch is what happens BETWEEN the links. Think of each stanza as a springboard from which you are going to jump. As your mind leaps (and you think you know where the poem is going) you should be forced to make a somersault in order to land upright in the next link. It is the twist your mind makes between links that makes renga interesting. (Reichhold 1995)

Renga takes place between performers, text, environments and audience. A writer participant in a renga must attend to drawing syntagmatic connections with the preceding verse as well as leaving opening for the writer of the next verse. In other words, an awareness of audience and reader responses is embedded within the act of writing. 
In January 2011, I performed in a renga (Fluxus Interruptus) with some of my Twitter poetry community.@marousia,@peterwilkins1,@bookwriter222, @amoz1939 and@remittancegirl were the renga performers. We followed the conventions outlined in wikipedia for Kasen renga

(http://en.wikipedia.org/wiki/Renga). The conventions follow that of a polite social gathering. Normally a renga opens with small talk about the weather and references to flowers and nature, the middle part is loose where various themes such as love, religion and politics are discussed, the last section may become disjointed as the party winds up. Traditionally, renga forms have this syllabic pattern, 5/7/5, 7/7, 5/7/5, 7/7 and so on. The $7 / 7$ verses may be thought of as clapping, or applause.

We marked each verse with the hash tag \#rengachange so that we could keep track of the verses as well as the turn-taking. The poem was composed in the public Twitter timeline over two days to accommodate time zone constraints. Two people were in the UK, two were in South East Asia and I was in Melbourne, Australia. The opening two verses of Fluxus Interruptus (Wilkin 2011) show a conventional opening with references to the weather and nature. The second stanza employs a meme in the form of cherry blossom, which symbolises a Zen aesthetic:

1. Under a cool moon/ the earth slumbers, breathes softly/ stillness and shadows

2. A gentle western breeze lifts / petals from a cherry tree

The poem continues in this polite vein until a stranger arrives about one third of the way through to disrupt the atmosphere:

11. horizonal rain / steals the stranger's hat and laughs / gifts it to the wind

12. The hat staggers drunkenly/ spins wildly on the pond's brink

A metaphor of a dinner party is reasserted as the sake flows. This line also signals that it is time to make the links between verses quite loose.

18. Feast of eels and sake/ appears for the dinner guests

The party begins to draw to a close with some guests drunkenly dozing, others flirting and some retiring for the night:

28. Sated guests lie on futons/ soothed by ghostly lullabies 29. An exchange, a glance / a frisson of excitement / quivers up the spine

30. In the corner the koto / sounds one dark abandoned note 31. Kimonos rustle/ the sound of slapping rhythms/ paper screen snaps shut

In the final verse the guests depart, returning to their own lives:

36. With lightening speed, he strikes / the gods of change start dancing

Peter Wilkin's blog post for Fluxus Interruptus provided a description of the process of writing the renga live in Twitter. In it he acknowledged a debt to Dada as well as to Japanese aesthetics:

Despite our moments of confusion the predominant feeling that ran the whole way through this exercise was one of great fun. It 
did not seem to matter to any of us if we strayed from accepted procedure or if our verses lacked continuity. On the contrary, we were poetic rebels $\&$ celebrated the fact that a degree of Dadaism had crept into our work as we 'laughed in the face of order \& convention'. (Wilkin 2011)

\section{Exploring forms together}

Sharing images in Twitter is remarkably easy. Another Japanese form that has gathered momentum because of this feature is haiga, which is poetry that combines haiku with visual images. The poets Yosa Buson (1716-1784) and Takebe Sōchō (1761-1814) are famous proponents of this form.A key aesthetic of haiga is that the poem and visual image should have a balanced relation where neither one dominates the other. The connection can be a tangent or juxtaposition so that the artwork or photograph is not necessarily an obvious visual representation of the words (Addiss \& Yamamoto 1995).

Within the context of the timeline, images and photographs are read as status updates and/or poems. Typically the Twitter update links to another site in the web interface. The example below illustrates the ease with which haiga can be shared:

cirrusdream polona

\#photo \#haiga :: blossom viewing / an equilibrist / steals the show http://twitpic.com/4gnc5z (Cirrusdream 2011)

The link shows the full haiku form haiga by cirrusdream including a photograph of a bee upside down clinging to a daffodil.

Gogyohka is a yet another form borrowed from Japanese poetry, pioneered by the Japanese poet Enta Kusakabe, which has also gathered popularity among poets. It is similar to tanka but has no formal rules regarding metre and does not require the third line to be a pivot line. It translates literally as 'five-lineverse'. Nevertheless it has an underlying Zen aesthetic that Kusakabe describes:

The single most important thing for people is their central axis - the part of them that constitutes their very essence - and the most important thing for the self is to recognize and understand that inner, central axis. Once you are aware of what is most important to you, then you are able to build your own system of values in relation to it. This allows you to create a standard by which you can judge the relative importance of the various aspects of your life and the world around you. When you are able to do this, the stress in your life naturally falls away. This is because stress comes from the inability to distinguish between what is and is not important; if you treat everything in your life with equal importance, then you become upset when, inevitably, some things do not go as well as you would like them to. (Kusakabe 2011)

Thus, each line in a gogyohka has equal weight. Gogyohka has also shifted into the haiga forms combining a visual image with a five-line-verse.

@ gennepher a huge bird/ spread its wings/ in the sky/ the land/ darkened \#gogyohka \#haiga picture here http://bit.ly/ffUZFU

(taken from the Twitter stream, also at Gennepher 2011) 
A subtle connection is drawn between the image and the verse to create a poetic moment where the order of lines entices the reader to shuffle them around to unpack the layers of meaning. The image depicts an x-ray like profile of a bird. The link in the Twitter timeline takes the reader to Gennepher's blog rather than directly to the haiga. The hash tags ensure that the poem will reach its target readers who are on Twitter at the time. So the invitation here is to stay a while and read through the other gogyohka, haiga and haiku this poet has on her blog (Gennepher 2011).

The ease of being able to switch between the Twitter timeline and other sites has facilitated the creation of poets' communities through linking blogs to each using status updates to let people know when there are new posts. An example of this is One Stop Poetry, the winner of the 2011 Shorty Award for Art; the Shorty Awards were created to honour 'the best people and organizations producing short-form, real-time social media content' (Shorty Awards 2011). The One Stop Poetry community originated through collaboration between Pete Marshall, a British poet and American poets Adam Dustus, Leslie Moon and Brian Miller. The aim of the community is to share poetry across the globe and to provide feedback. Each week over 100 participants provide links to poems on their blogs, visit each others' blogs and provide comments. The blog links are publicised through Twitter by both the poets and the administrators of the website (One Stop Poetry 2011).

Through Twitter, the reach of National Poetry Writing Month held in April in the United States has transcended national boundaries and become an international event (NaPoMonWri 2011). Many took up the challenge to write a poem each day through April. Blogs arose to provide stimulus words and forums to support poets who chose to participate. The connection to Twitter provided individual blogs with immediacy so that people can publicise their creative practice to others who care and are interested. Writers receive the benefits of belonging to a community of peers as well as the opportunity to perform in virtual 'salons' to an appreciative audience.

\section{Extending reading and writing through Twitter}

The Twitter stream itself has a meditative ephemeral quality that may stand in opposition to the frantic pace of contemporary life. It can be an invitation to poiesis; to play with words, to improvise with others and to connect poetic objects together. I propose that artists, writers and poets embrace Twitter and social media as new mediums ready to be appropriated and colonised for poetic performances with both words and visual images.

Participation in Twitter streams has already extended reading and writing towards innovative practices because of its social aspects. Poetry writing in this context is a shared social ritual. It has also resulted in the renaissance of older forms, especially Japanese forms such as tanka, haiku, and haiga. It has also facilitated the adoption of newer less constrained forms such as senryu and gogyohka. Literary journals have appeared to provide editorially curated spaces for poets experimenting with short form poetry.

From my point of view as an artist and a poet, the contempt people express about the banality of Twitter is unwarranted. Each day I encounter poetic language acts that inspire me in my Twitter timeline. I have found it to be a wonderful tool to enrich my own creative practice. It has introduced me to forms such as renga, gogyohka and haiga, which I have incorporated into my practice. It also provides me with feedback. No longer do I write alone for an 
imaginary or abstract reader with whom I may never have contact. Instead I write for concrete readers and peers who engage with my words virtually as soon as I send them either within my timeline or as comments on my blog. Writing in this context takes on a performance as well as a social dimension.

\section{Works cited}

Abrams, MH \& G Harpham 2009 A Glossary of Literary Terms, 9th Edition. Boston: Wadsworth Cengage Learning return to text

Aciman, A \& E Rensin 2009 Twitterature: The World's Greatest Books in Twenty Tweets or Less. New York: Penguin return to text

Acorn: A Journal of Contemporary Haiku http://www.acornhaiku.com/acornhaiku/Home.html (accessed 18 September 2011) return to text

Addiss, S \& F Yamamoto 1995 Haiga: Takebe Sōchō and the Haiku-painting tradition. Honolulu: University of Hawaii Press return to text

Allsop, R 1999 'Performance Writing', PAJ: A Journal of Performance and Art 21, 1 (January): $76-80$ return to text

American Tanka http://www.americantanka.com/about/ (accessed 18 September 2011) return to text

Ayers, D 2004 'H.D., Ezra Pound and Imagism', in Modernism: a Short Introduction. Blackwell, Wiley Online Library http://onlinelibrary.wiley.com/doi/10.1002/9780470776285.ch1/summary (Accessed 31 May 2011) return to text

Borges, J 1999 [1975] El libro de arena. Madrid: Alianza Editorial SA return to text

Bourdieu, P 1977 Outline of the Theory of Practice. Cambridge: Cambridge University Press return to text

Burgess, Jean 2008 'All Your Chocolate Rain Are Belong to Us?': Viral Video, Youtube and the Dynamics of Participatory Culture', in G Lovink \& S Niederer (eds) The VideoVortex Reader. Amsterdam: Institute of Network Cultures, pp. 101-11 return to text

Celebrity Tweet, 2011 'Neil Gaimon'

http://www.celebritytweet.com/neilhimself/link/4837873679/(accessed 23 October 2011) return to text

Cirrusdream 2011 'Polona' Twitpic http://twitpic.com/4gnc5z (accessed 10 April 2011) return to text

Coates, S 2010 'The Language Of Mobile Phone Novels: Japanese Youth, Media Language And Communicative Practice', Crises and Opportunities: Past, Present and Future. Proceedings of the 18th Biennial Conference of the Asian Studies Association of Australia, University of Adelaide, 5-8 July $2010 \mathrm{http}$ ://asaa.asn.au/ASAA2010/reviewed_papers/CoatesStephanie.pdf (accessed 10 April 2011) return to text

Debman, M 2010 'Is the standard of children's literacy declining because of texting or online social networking?' Leading English language children's educational papers

http://www.daily7-daily10.com/viewpoint/2010/11/26/is-the-standard-of-children's-literacydeclining-because-of-texting-or-online-social-networking/ (accessed 10 April 2011) return to text

Gaiman, N \& the Twitterverse 2009 'BBC Audio: Hearts, Keys, and Puppetry by Neil Gaiman and the Twitterverse', SFFaudio http://www.sffaudio.com/?p=13878 (accessed 4 May 2011) return to text

Gennepher 2011 Gennepher: Gogyoka, Haiku and Haiga http://gennepher.blogspot.com/2011/03/haiku-and-gogyohka.html (accessed 10 April 2001) return to text 
Gheorghe, A nd The Longest Poem in the World http://www.longestpoemintheworld.com/ (accessed 17 May 2010 and 6 April 2011) return to text

Hayes, S 2011 'The Poets and the Geeks', Arts Hub http:/www.artshub.com.au/au/newsarticle/opinions/arts/the-poets-and-the-geeks-183665 (accessed 18 April 2011) return to text

Hjorth, L 2009 'Cartographies of the mobile: the personal as political', in L Hjorth and G Goggin (eds) Waiting to participate: emerging modes of digital storytelling, engagement and online communities, Special issue of Communication, Policy and Culture (formerly Southern Review) 42, 2: 24-44 return to text

Kikaku, T 2006 'An Account of Our Master Basho’s Last Days’ (trans N Yuasa) Simply Haiku 4, 3 (Autumn) http://simplyhaiku.com/SHv4n3/features/Nobuyuki.html (accessed 21 May 2011) return to text

Kusakabe, E 2011Gogyohka Junction: Five line Poetry http://gogyohka.ning.com/page/about-1 (accessed 4 April 2011) return to text

Lacan, J 1977 Écrits (trans A Sheridan). London: Tavistock return to text

Lawlor, W 2005 Beat Culture: Lifestyles, Icons, and Impact. Santa Barbara: ABC-CLIO return to text

Leadbeater, C 2009 'We Think: The Power of Mass Creativity', IA TV

http://iatelevision.blogspot.com/2009/02/charles-leadbeater-we-think-power-of.html (accessed 5 May 2011) return to text

NaPoMonWri 2011, National Poetry Writing Month 2011, http://www.napowrimo.net/ (accessed October 23, 2011) return to text

One Stop Poetry 2011 http://onestoppoetry.com/ (accessed 23 March 2011) return to text

Prune Juice: Journal of Senryu and Kyoka http://prunejuice.wordpress.com/ (accessed 20 May 2011) return to text

Raley, R 2009 'Mobile Media Poetics', Proceedings of the Digital Arts and Culture Conference 2009, UC Irvine, eScholarship: University of California

http://www.escholarship.org/uc/item/01x5v98g (accessed 1 November 2010) return to text

Reichhold, J 1995 'Jump Start to Renga' http://www.ahapoetry.com/r_info.htm\#start (accessed 25 May 2011) return to text

Riffaterre, M 1983 Text Production. New York: Columbia University Press return to text

Ronan 1995 'We need Renga!' Ahapoetry.com http://www.ahapoetry.com/r_info.htm\#need (accessed 18 September 2011) return to text

Schechner, R 1985 Between Theater and Anthropology. Philadelphia: University of Pennsylvania Press return to text

Schechner, R 2002 Performance Studies: An Introduction. London: Routledge return to text

Young, S 2008 'Beyond the Flickering Screen: Re-situating e-books' M/C Journal 11, 4

http://dev.mediaculture.ci.qut.edu.au/ojs/index.php/mcjournal/article/viewArticle/61

Shorty Awards 2011 http://shortyawards.com/ (accessed 10 March 2011) return to text

Simply Haiku: A Quarterly Journal of Japanese Short Form Poetry 2010

http://simplyhaiku.com/ (accessed 15 May 2011) return to text

Sullivan, J 2008 'Thumbs down to the Nokia Novel' The Age A3 section, (9 February) 2008): 28 return to text

Ulin, DL 2009 'The Lost Art of Reading.' LA Times (9 August)

http://www.latimes.com/entertainment/news/arts/la-ca-reading9-2009aug09,0,4905017.story

(accessed 16 September 2011)

Watson, T 2007 'Twitter Poetry' (13 March) My dirty life and times,

http://tomwatson.typepad.com/tom_watson/2007/03/index.html (accessed 16 October 2011) 
return to text

Wilkin, P 2011 'Fluxus Interruptus: when renga joined the avant-garde', Peter Wilkin's BLOG http://peterwilkin1.blogspot.com/2011/01/fluxus-interruptus-when-renga-joined.html (accessed 24 March 2011) return to text

Marsha Berry is a Senior Lecturer in the School of Media and Communication at RMIT University, Australia. She has a PhD in English from Monash University and an MEd(Hons) in children's storytelling from James Cook University, North Queensland. In the past, she taught interactive media and narrative. Currently she lectures in Asian media culture and writing angles for undergraduate degrees. She supervises postgraduate research students across a range of topics concerned with new media, narrative and creative writing, cultural studies and mobility. Her current research and art practice includes mobile social media, locative media, and Vietnam and memory studies.

\section{TEXT}

Vol 15 No 2 October 2011

http://www.textjournal.com.au

Editors: Nigel Krauth \& Kevin Brophy

Text@griffith.edu.au 